\title{
Study of the fragmentation pathways of dimethyl disulfide derivative of 2-methyl-1,4-pentadiene by GC/MS to locate the double bonds in substituted unsaturated compounds
}

\author{
C. Pepe ${ }^{1, *}$, H. Sayer ${ }^{1}$, S. Ledoux ${ }^{2}$ and J. Dagaut ${ }^{3}$ \\ ${ }^{1}$ Laboratoire de Spectrochimie Moléculaire, Université P. et M. Curie, case 49, 75252 Paris Cedex 5, France \\ ${ }^{2}$ Laboratoire de Chimie des heterocycles, Université P. et M. Curie, case 49, 75252 Paris Cedex 5, France \\ ${ }^{3}$ Laboratoire de Physique et Chimie Marines, Université P. et M. Curie, case 134, 75252 Paris Cedex 5, France
}

\begin{abstract}
An experimental study has been employed to examine the loss of $\mathrm{CH}_{3} \mathrm{SH}$ from the dimethyl disulfide (DMDS) derivative of 2-methyl-1,4-pentadiene (cyclic thioether). This loss is particulary important to locate the double bonds in mono, di and tri-unsaturated compounds after addition of DMDS. This work shows that the migration of a $\mathrm{H}$ atom in the $\beta$ or in a other position relative to the sulfur atom is possible. This result shows that this method of the location of the double bonds in unsaturated compounds is also possible when the carbon atoms in the $\beta$-position relative to the sulfur atom are substituted.
\end{abstract}

Key words. GC/MS - DMDS - double bonds.

\section{Introduction}

The determination of the double bond positions in mono and diunsaturated esters has been studied by using their dimethyl disulfide (DMDS) derivatives. If the number of methylene groups which separates the two double bonds is less than 4 , a cyclic thioether is formed and the fragmentation observed, after electron impact at $70 \mathrm{eV}$, has permitted unequivocal determination of the double bond positions for alkadienes and esters [1-6].

The DMDS derivative (a cyclic thioether) of 2-methyl1,4-pentadiene has been studied by mass spectrometry in a previous paper [7]. The mass spectrum (Fig. 1) shows the presence of a base peak at $\mathrm{m} / \mathrm{z} 113$ and fragment ions at $\mathrm{m} / \mathrm{z}$ 161 and 147 resulting of the loss of $\mathrm{CH}_{3} \mathrm{~S}^{*}$ or $\mathrm{CH}_{3} \mathrm{SCH}_{2}{ }^{\circ}$ respectively from the molecular ion. In turn, these fragment ions $\mathrm{m} / \mathrm{z}, 161$ and 147 lose methanethiol $\left(\mathrm{CH}_{3} \mathrm{SH}\right)$ to give respectively the ions at $\mathrm{m} / z, 113$ and 99 . This loss of $\mathrm{CH}_{3} \mathrm{SH}$ is essential for interpretation of the mass spectra of DMDS derivatives of unsaturated compounds and to locate the double bonds.

The structures of the fragment ions at $\mathrm{m} / \mathrm{z} 113$ and 99 were investigated by using $a b$ initio calculations, in particular by calculation of the values of the relative energies of the isomeric structures. In each case, the loss of $\mathrm{CH}_{3} \mathrm{SH}$ was considered as a migration of the hydrogen atom bonded to the carbon atom in the $\beta$-position relative to the sulfur atom.
We report in this work a study of the loss of $\mathrm{CH}_{3} \mathrm{SH}$ by migration of a hydrogen atom no bonded to $\mathrm{C}$ in the $\beta$-position relative to the sulfur atom.

\section{Experimental}

\section{Sample preparations and mass spectrometry}

2-methyl-1,4-pentadiene and 2,4-dimethyl-1,4-pentadiene $(50 \mu \mathrm{g})$ were treated in $100 \mu \mathrm{L}$ of hexane by addition of $100 \mu \mathrm{L}$ of DMDS and a solution of $20 \mu \mathrm{L}$ of iodine $(60 \mathrm{mg}$ of iodine in $1 \mathrm{~mL}$ of diethyl ether). The reaction was carried out in a closed tube for two days at $50{ }^{\circ} \mathrm{C}$. The excess of iodine was reduced with sodium thiosulfate solution $(5 \%$ in water). The organic phase was removed and the excess of DMDS was evaporated. The dry extract was diluted with $50 \mu \mathrm{L}$ of hexane and then analysed by GC/MS.

To synthesize the 2,4-dimethyl-1,4-pentadiene, $10 \mathrm{~mL}$ of a solution of isopropenylmagnesium bromide $\left(0.5 \mathrm{~mol} \mathrm{~L}^{-1}\right)$ in THF were added dropwise under $\mathrm{N}_{2}$ and moderate stirring to $0.4 \mathrm{~mL}$ of 3-chloro-2-methyl-propene, then shaken at room temperature during 12 hours. The mixture was hydrolysed by $1 \mathrm{~mL}$ of $\mathrm{NH}_{4} \mathrm{Cl}$ satureted solution, dried over $\mathrm{Na}_{2} \mathrm{SO}_{4}$, and distilled under atmospheric pressure.

Electron ionization mass spectra were obtained using a Nermag R10-10 quadrupole mass spectrometer coupled to a Varian Model 3400 gas chromatograph. The sample was

* Correspondence and reprints.

Received October 06, 1998; revised March 09, 1999; accepted March 18, 1999. 


\section{Original articles}

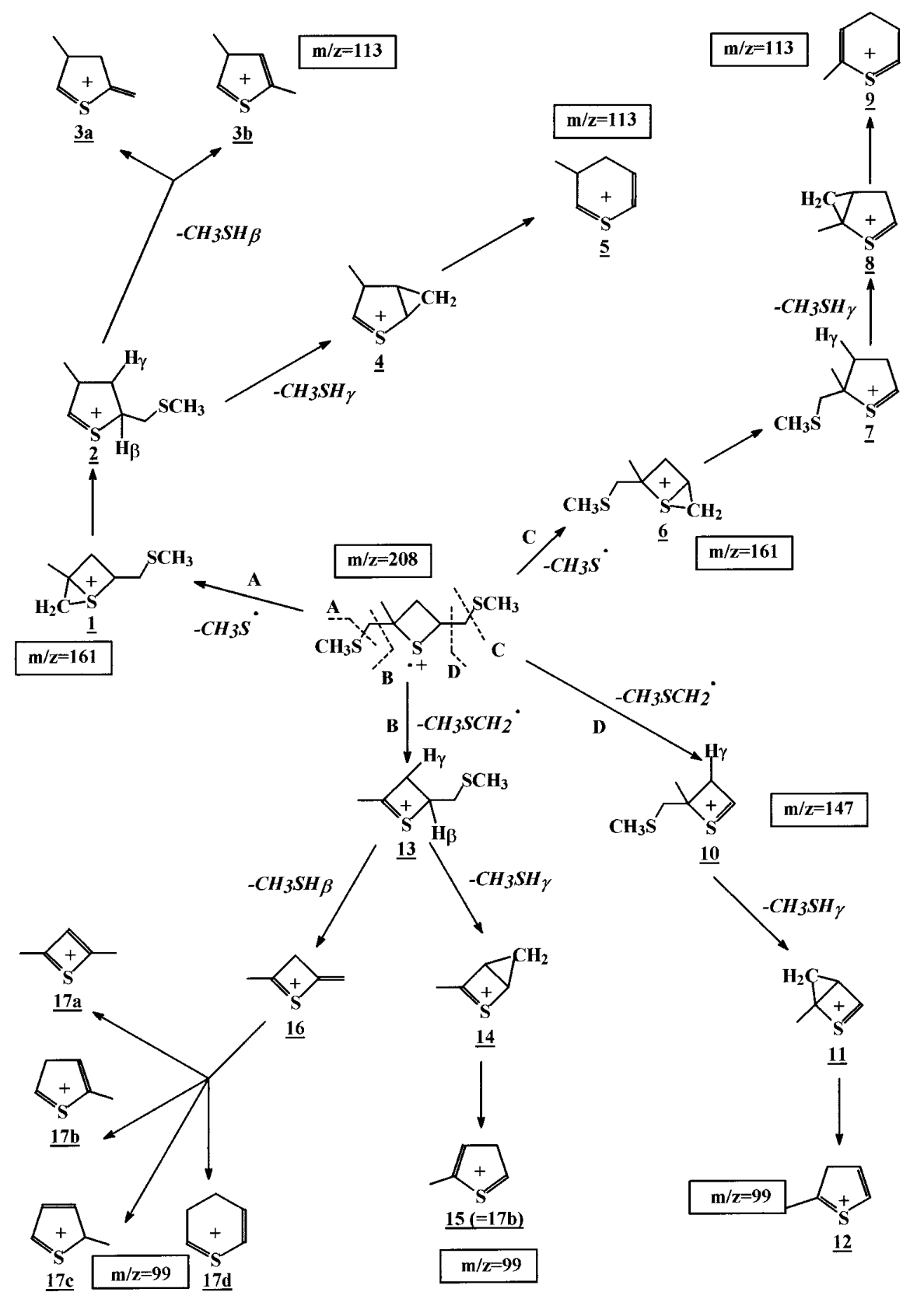

Scheme 1. Fragmentation pathways of the DMDS derivative of the 2-methyl-1,4-pentadiene.

injected in the septum-equipped programmable injector (SPI) mode. The column employed was a fused-silica capillary $(30 \mathrm{~m} \times 0.25 \mathrm{~mm}$ i.d., $0.2 \mathrm{~mm}$ film-thickness) coated with DB5 phase (Chrompack). The column temperature was increased at $10{ }^{\circ} \mathrm{C} / \mathrm{min}$ from 100 to $280{ }^{\circ} \mathrm{C}$.

$A b$ initio calculations used the Gaussian $98 \mathrm{~W}$ quantum chemical package. Relative energies were obtained from higher level calculations employing the standard polarized basis set $\left(6-31 G^{*}\right)$, optimized structures were confirmed as minima (equilibrium structures) or saddle points (transition structures) by evaluation of the full set of harmonic vibrational frequencies at $\mathrm{B} 3 \mathrm{LYP} / 6-31 \mathrm{G}^{*}$ level and the harmonic vibrational frequencies were calculated at the same level and used to derive zero-point vibrational (ZPE) corrections to relative energies [8-10].

\section{Results and discussion}

To prove the hypothesis of the migration of a hydrogen atom bonded to $\mathrm{C}$ in a position which is not the $\beta$-position 


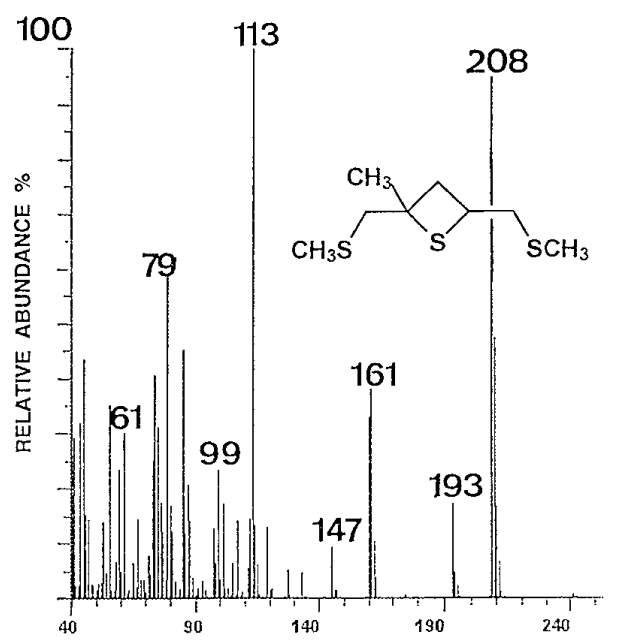

Figure 1. Mass spectrum of the DMDS derivative of the 2-methyl -1,4-pentadiene.

relative to the sulfur atom, a compound without a hydrogen atom bonded to $\mathrm{C}$ in the $\beta$-position, the 2,4-dimethyl-1,4pentadiene, has been synthesized. The product resulting of the reaction between this compound and the DMDS is a four-membered cyclic thioether since only one methylene group separates the double bonds [1-6].

The mass spectrum of the DMDS derivative of this compound is presented in figure 2 . The presence of the fragment ion at $\mathrm{m} / \mathrm{z} 113$ corresponding to the loss of $\mathrm{CH}_{3} \mathrm{SH}$ from the fragment ion $\left[\mathrm{M}^{+\bullet}-\mathrm{CH}_{3} \mathrm{SCH}_{2}\right]^{+}$which allows us to locate the double bonds, prove that a $\mathrm{H}$ atom in the $\beta$-position is not essential to observe this loss of methanethiol. The presence of the fragment ion at $\mathrm{m} / \mathrm{z} 127$ obtained in the mass spectrum of the DMDS derivative of 2,5-dimethyl-1,5-hexadiene, a fivemembered cyclic thioether without a $\mathrm{H}$ atom in the $\beta$-position relative to the sulfur atom, presented in figure 3 , shows also the loss of $\mathrm{CH}_{3} \mathrm{SH}$ from the fragment ion at $\mathrm{m} / \mathrm{z} 175$, that proves that this migration is systematic and independant of the number of the carbon atoms in the ring.

Scheme 1 shows the possible fragmentation pathways obtained from the DMDS derivative of 2-methyl-1,4-pentadiene in accordance with previous works [11-12]. Only the possibility of the transfert of a $\mathrm{H}$ atom from a $\gamma$-position which is the most probable is viewed. The structures of the fragment ions at $\mathrm{m} / \mathrm{z}, 113$ and 99 are different according to the pathway $\mathrm{A}$ or $\mathrm{C}$ (loss of $\mathrm{CH}_{3} \mathrm{~S}^{\bullet}$ from the molecular ion), and $\mathrm{B}$ or D (loss of $\mathrm{CH}_{3} \mathrm{SCH}_{2}{ }^{\circ}$ from the molecular ion), respectively.

Concerning the isomeric structures (respectively for the pathways A and B), in order to choice between these structures, their geometries and their energies were calculated according to the method presented in the experimental section. The results listed in tables I and II show that the fragment ion (3b) at $m / z 113$ is probably the most stable after

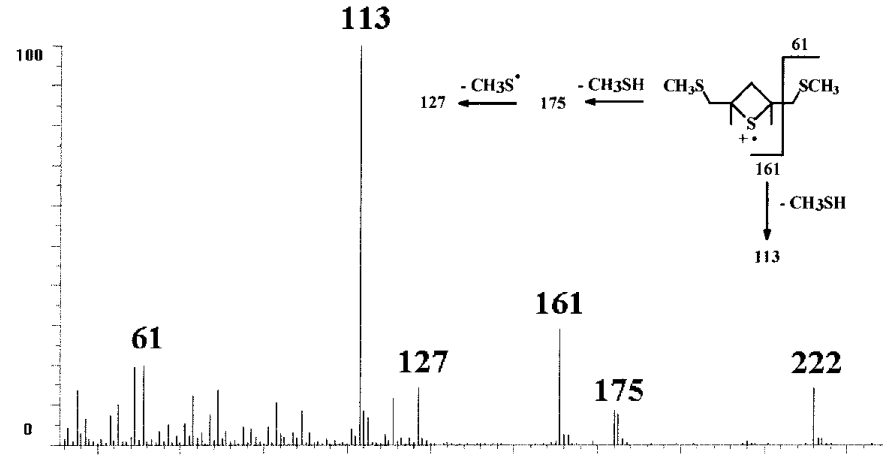

Figure 2. Mass spectrum of the DMDS derivative of the 2,4dimethyl-1,4-pentadiene.

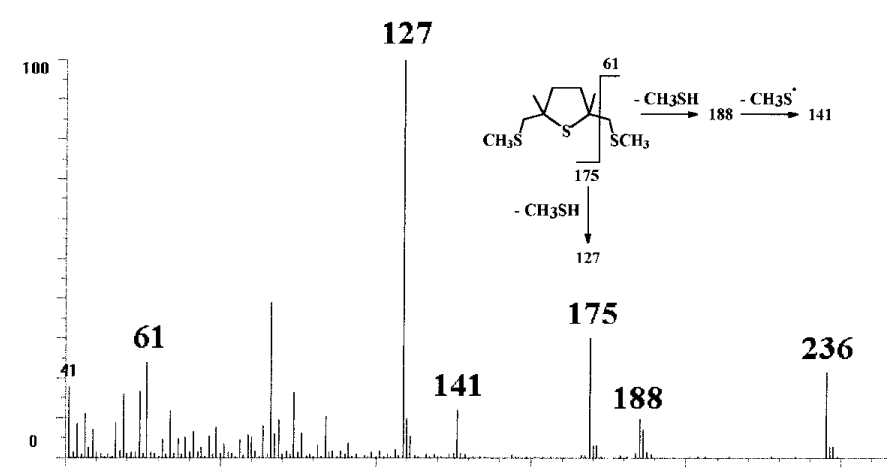

Figure 3. Mass spectrum of the DMDS derivative of the 2,5dimethyl-1,5-hexadiene.

Table I. Calculated total energies $\left(E_{\mathrm{T}}\right)$ in hartree, with ZPVE corrections, and $\Delta E$ energies relative to the most stable structure $(\mathrm{kJ} / \mathrm{mol})$ for the structures obtained from the pathway A.

\begin{tabular}{lcc}
\hline Species & $E_{T}$ & $\Delta E$ \\
\hline $3 \mathrm{a}$ & -631.949 & 31.5 \\
$\mathrm{~b}$ & -631.961 & 0 \\
\hline
\end{tabular}

Table II. Calculated total energies $\left(E_{\mathrm{T}}\right)$ in hartree, with ZPVE corrections, and $\Delta E$ energies relative to the most stable structure $(\mathrm{kJ} / \mathrm{mol})$ for the structures obtained from the pathway B.

\begin{tabular}{lcc}
\hline Species & $E_{T}$ & $\Delta E$ \\
\hline $17 \mathrm{a}$ & -592.499 & 404 \\
$17 \mathrm{~b}$ & -592.536 & 307 \\
$17 \mathrm{c}$ & -592.653 & 0 \\
$17 \mathrm{~d}$ & -592.520 & 349 \\
\hline
\end{tabular}




\section{Original articles}

the loss of $\mathrm{CH}_{3} \mathrm{SH}(\beta)$ and that the fragment ion $(17 \mathrm{c})$ at $\mathrm{m} / z$ 99 is also probably the most stable after the loss of $\mathrm{CH}_{3} \mathrm{SH}(\beta)$.

It is obvious that the results show only that the $\mathrm{H}$ atom does not come from a $\beta$ position and the mechanism of the transfer of a $\mathrm{H}$ atom from a $\gamma$-position can be proven only by labelling all $\mathrm{H}$ atoms at this position in the DMDS derivative.

\section{Conclusion}

This experimental study proves that the migration of a $\mathrm{H}$ atom in a other position that the $\beta$-position relative to the sulfur atom is possible in the essential mechanism of the loss of $\mathrm{CH}_{3} \mathrm{SH}$ in the DMDS derivatives allowing to locate the double bonds. So, this result shows that this method of the location of the double bonds in unsaturated compounds is suitable when the $\mathrm{C}$ atoms in the $\beta$-position are substituted such as encountered in the natural environment.

\section{References}

1. Vincenti, M.; Guglielmetti, G.; Cassani, G.; Tonini, C. Anal. Chem. 1987, 59, 694-699.
2. Scribe, P.; Pepe, C.; Barouxis, A.; Fuche, Ch.; Dagaut, J.; Saliot, A. Analusis 1990, 18, 284-288.

3. Pepe, C.; Dagaut, J. Scribe, P.; Saliot, A. Org. Mass. Spectrom. 1993, 28, 1365- 1368.

4. Pepe, C.; Dizabo, P.; Dagaut, J.; Balcar, N.; Lautier, M. F. Eur. Mass. Spectrom. 1995, 1, 209-211.

5. Pepe, C.; Balcar, N.; Dizabo, P.: Dagaut, J.; Saliot, A.; Couffignal, R.; Sayer, H. Rapid Commun. In Mass Spectrom. 1995, 9, 1576-1579.

6. Pepe, C.; Sayer, H.; Balcar, N.; Dagaut, J.; Couffignal, R. Eur. Mass. Spectrom. 1996, 2, 376-378.

7. Pepe, C.; Sayer, H.; Dagaut, J. Eur. Mass. Spectrom. 1997, 3, 400-403.

8. Becke, A. D. J. Chem. Phys. Rev. 1993, 98, 5648-5655.

9. Krishnan, R.; Binkley, J. S.; Seeger, R.; Pople, J. A. J. Chem. Phys. 1980, f72, 650-658.

10. Hariharan, P. C.; Pople, J. A. Theo. Chim. Acta 1973, 28, $213-$ 218

11. Dill, J. D.; McLafferty, F. W. JACS 1979, 101, 6526-6531.

12. Nobes, R. H.; Bouma, W. J.; Radom, L. JACS 1984, 106, 2774-2781. 